\title{
Mapping Cases of Tuberculosis Distribution and Treatment Outcomes using Geographical Information System - The Case of Birim Central Municipality, E/R - Ghana
}

\author{
Boaz Ahulu \\ Kwame Nkrumah University of \\ Science and Technology \\ Department of Computer Science \\ Kumasi - Ghana
}

\author{
Frimpong Twum \\ Kwame Nkrumah University of \\ Science and Technology \\ Department of Computer Science \\ Kumasi - Ghana
}

\author{
J. B. Hayfron Acquah \\ Kwame Nkrumah University of \\ Science and Technology \\ Department of Computer Science \\ Kumasi - Ghana
}

\begin{abstract}
Analyzing the spatiotemporal distribution of tuberculosis (TB) is a very important way to understand its epidemiology thereby helping to identify geographic regions at higher risk and to enable proper control and resource allocation. This study was undertaken to ascertain the spatiotemporal distribution of TB cases and treatment outcomes in the Birim Central Municipality (BCM) in the Eastern Region (E/R) of Ghana for the period 2012-2016 and to recommend appropriate preventive measures. In this retrospective study, the locations of the total of $268 \mathrm{~TB}$ cases identified from 2012-2016 were geocoded on the BCM digital maps. Spatial visualization using choropleth maps, network analysis, and service area analysis of ArcGIS10.2 was used to identify the geographic concentration of cases and the various treatment outcomes as well as proximity of patient community to health facility. A questionnaire was also used to collect primary data from TB patients diagnosed in year 2017. This data was analyzed using SPSS version 21. The study identified five main communities as hot spots of TB in the municipality with variations in other communities. It was also found that other non-spatial factors such as socioeconomic factors and stigmatization highly influence treatment outcome. Reducing stigmatization, regular sensitization of health staff who are not directly involved in tuberculosis care, and using a formerly cured TB patient as a peer educator were some of the best ways identified to help improve positive treatment outcomes in the municipality.
\end{abstract}

\section{General Terms}

Geographical information system, hot spots, mapping

\section{Keywords}

Tuberculosis distribution, treatment outcomes, spatiotemporal distribution, GIS

\section{INTRODUCTION}

Tuberculosis (TB), classified as one of the three diseases of special public and global health importance, has received much attention to the extent of establishing a whole unit under the Ghana Health Service structures for its control. This disease which has enormous economic and public health burden, has affected a sizeable number of Ghanaians due to its ability to spread easily with associated increased in mortality rates (Yang et al, 2012). In spite of the efforts by the National Tuberculosis control program (NTP) in instituting control measures on the disease in the country, there remain some challenges which need to be addressed (Amo-Adjei, 2013) as case load keep increasing.

Li et al (2014) were of the view that for an effective allocation of scarce resources, it is imperative to have deeper insight into spatial variation factors of TB so that national programs can achieve better results. In the year 2013, out of all ten regions in Ghana, Eastern region recorded the highest prevalence of Tuberculosis and HIV co-infection of $33.4 \%$ and the least 9.4\% recorded in Upper East region (CCM - Ghana, n.d). It is believed strongly by this study that mapping the prevalence of tuberculosis in the Birim Central Municipality is one of the surest ways to target populations for control of tuberculosis and also to ascertain treatment outcomes in relation to a particular geographic area in the municipality. This study intends to ascertain the hot spots of tuberculosis, the types of treatment outcomes in a given geographic location, and the extent of impact of proximity of health facilities to patients locality and how it contribute to a particular treatment outcome. It is hope the study outcome will help address some of the challenges in the tuberculosis control program in the Birim Central municipality.

\subsection{Research Objectives}

2. To ascertain the spatio-temporal distribution pattern of tuberculosis cases and treatment outcomes in the Birim Central Municipality.

3. To find out if proximity of health facilities to patients location have any influence on tuberculosis treatment outcome.

4. To suggest measures which can help improve the control of tuberculosis in the municipality

\section{LITERATURE REVIEW}

Tuberculosis, a disease which normally affects the lungs hence sometimes refer to as Pulmonary Tuberculosis (PTB), can also affect any other parts of the body (Extra-Pulmonary Tuberculosis [EPTB]). In Ghana as well as in other parts of the world, fear of stigmatization poses a big challenge for suspected individuals to report early to the nearest health facility for management (Møller et al., 2011). The delay in reporting cases therefore facilitate the spread of the disease. More importantly is the ability for service providers to detect cases which visits the hospital for other health reasons (Kripalani et al, 2007). Six important factors responsible for the delays include demographic, financial burden, stigmatization against the disease, distance to reach the health 
facility as rural folks have to travel longer hours, seeking care from quacks, and visiting several health facilities before actual diagnosis (Storla et al, 2008).

There are seven main treatment outcomes of TB treatment and include cure, treatment completed, treatment failure, defaulter or loss to follow up, transferred out and death (Espinal et al, 2000; Veen et al, 1998; WHO, 1997). The Ghana National TB control program however does not consider transferred out as a treatment outcome since all transferred cases need to continue with their treatment irrespective of where they end up (NTP, 2012).

Tadesse et al (2013) in their quest to establish any relationship between distance from the TB patients home and the financial constraints imposed on the patients as they travel to the treatment centres, collected information from TB patients who received treatment from only two health centres out of the many health facilities which provides services to the public. These patients irrespective of their geographical location have to collect the TB medications daily for the two month intensive phase and weekly for the remaining four months of treatment. Their study establishes that most of the TB patients lived in rural communities which were not within easy reach of the health facilities. Walking longer distances affected the treatment process as patients became exhausted physically. This resulted in most clients preferring the traditional healer persons who were very close to them and who services are at reduced costs. Even though their study did not use geographical information system to access the real problem of geographical accessibility, it concluded that geographical access and financial constraints were the major issues that affected the time of treatment initiation and compliance. A related study by Kolifarhood et al, (2015) concluded that waiting for cases to come to the hospital rather than pursuing them in their homes and communities and also, not following up on the patients to find out if they are adhering to the right way of taking the medicines leads to negative treatment outcomes.

One powerful automated ways of capturing, retrieving, and presenting spatial data is through the use of geographical information systems (GIS) (Clarke et al, 1996). GIS even though may have some limitations, it has many useful functions such as calculating distance between geographic locations, AND generating buffer area of required width around a point, line or area. In addition GIS also has the feature of selecting a map layer with a specific characteristic (Vine et al, 1997). Gupta and Shriram (2004) list benefits of using GIS which include identifying the areas where cases are clustered and therefore are at a higher risk of a disease, forecasting epidemics, and monitoring disease trend and interventions over time. It is therefore prudent for every public health official to employ the use of GIS for controlling diseases and other health events (Cromley \& McLafferty, 2011).

\section{METHODOLOGY}

A quantitative design using the purposive sampling technique was used in gathering the requisite retrospective data to describe the tuberculosis case distribution and outcomes of treatment as well as best ways of improving the TB control program in the study area. This study focused on the spatial analysis of TB disease distribution and outcomes of treatment. Both descriptive and inferential statistics methods were used to describe and analyzed the data.
The population for the study included TB cohorts in the Birim Central Municipality from 2012 to $2017 \quad(n=324)$ and all health personnel directly involved in TB care within the municipality $(n=20)$. Individual patient variables which were the subject of this investigation were extracted manually from the municipal TB register and recorded into excel sheet.

After accessing the patients' records and more importantly, their address to locate their homes, their individual locations were geographically coded on the Birim Central municipal base maps. The geo-coded data created from the hospital records were exported into the ArcGIS 10.2 software and overlaid with Birim Central Municipal base maps. The description of the data spatially was in the view to understand space patterns and relationships (Wise et al., 1995). Two approaches to analyzing the data spatially were undertaken as follows: network analysis and evaluating the density of distribution of tuberculosis and treatment outcomes using choropleth maps (Colantonio et al., 2011). The map actually brought out clearly the areas with concentration of tuberculosis in the study locality. Again, the map brought to light communities who are at higher risk of tuberculosis (hot spots) and those with relatively lower risk as well as areas where there are highly positive tuberculosis treatment outcomes in the Municipality as was the case in a related study by Mills et al, (2011). In order to ascertain how easy or difficult TB patients get access to treatment points in the municipality, the service area analysis was employed. Evaluating the distance travelled by patients to health facilities and the spatial distribution of cases within a municipality according to Huang et al, (2009) will help to assess the impact it will have on outcomes of treatment

\section{RESULT AND DISCUSSIONS}

This section illustrates the spatial distribution of TB cases identified for the years 2012 to 2016 in the Birim Central municipality. Visualizing the distribution of cases is an important aspect of epidemiological studies. This helps to generate hypothesis useful to identify factors influencing patterns of diseases. The use of maps to communicate how a given disease is distributed is helpful in identifying persons at high risk.

\subsection{Demographics of cases}

A total of $268 \mathrm{~TB}$ cases were reported during the five years period of study data (This exclude 56 cases for year 2017 who were interviewed). Of the total TB cases, 201 (75\% of the total cases) were smear positives cases (PTB +$)$ while $67(25 \%$ of the total cases) were smear negative (PTB-) and 7 (3\% of the total cases) were extra-pulmonary tuberculosis (EPTB). The spatial distribution of cases by communities is illustrated in the figures 1. Whiles Figure 2 presents mapping of cases managed in health facilities for the five years period.

\subsection{Treatment Outcomes of TB}

Out of the $268 \mathrm{~TB}$ cases recorded during the five years, 16 of the patients died, 179 were cured, 53 completed treatment, 7 were transferred out, 3 were treatment failures and 7 defaulted in seeking treatment. The spatial distribution of TB treatment outcome has also been mapped for the municipality. Figures 3 and 4 shows the general and specific outcomes for each of the communities in the municipality where TB was identified.

The death rate of TB cases per the various health facilities in the different communities is presented in figure 5

The treatment failure rate by the various communities from 2012 to 2016 is also illustrated by figure 6 . 


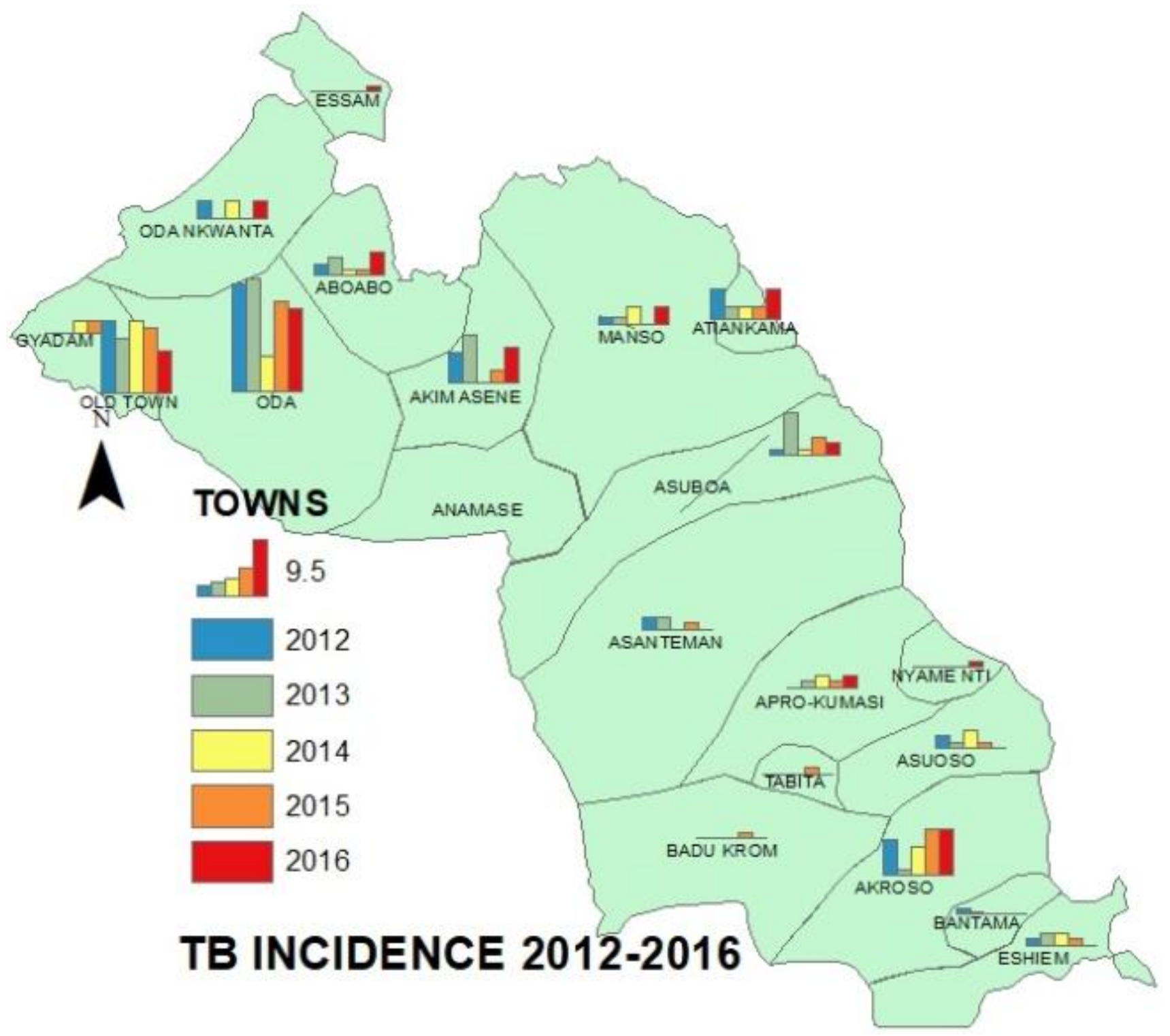

Figure 1: TB distribution by communities, 2012 - 2016, BCM 


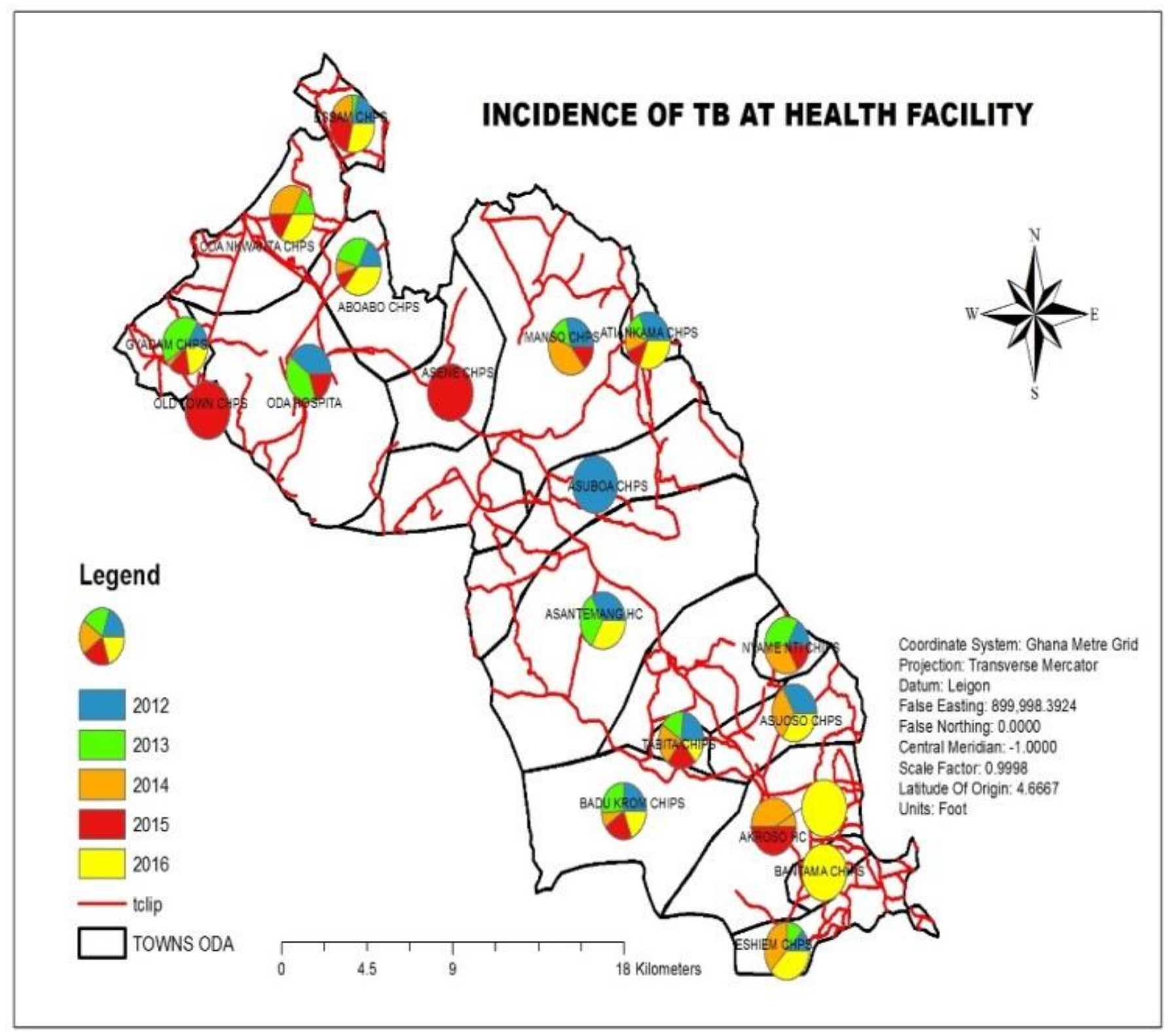

Figure 2: Cases Managed in Health Facilities, 2012 - 2016, BCM 


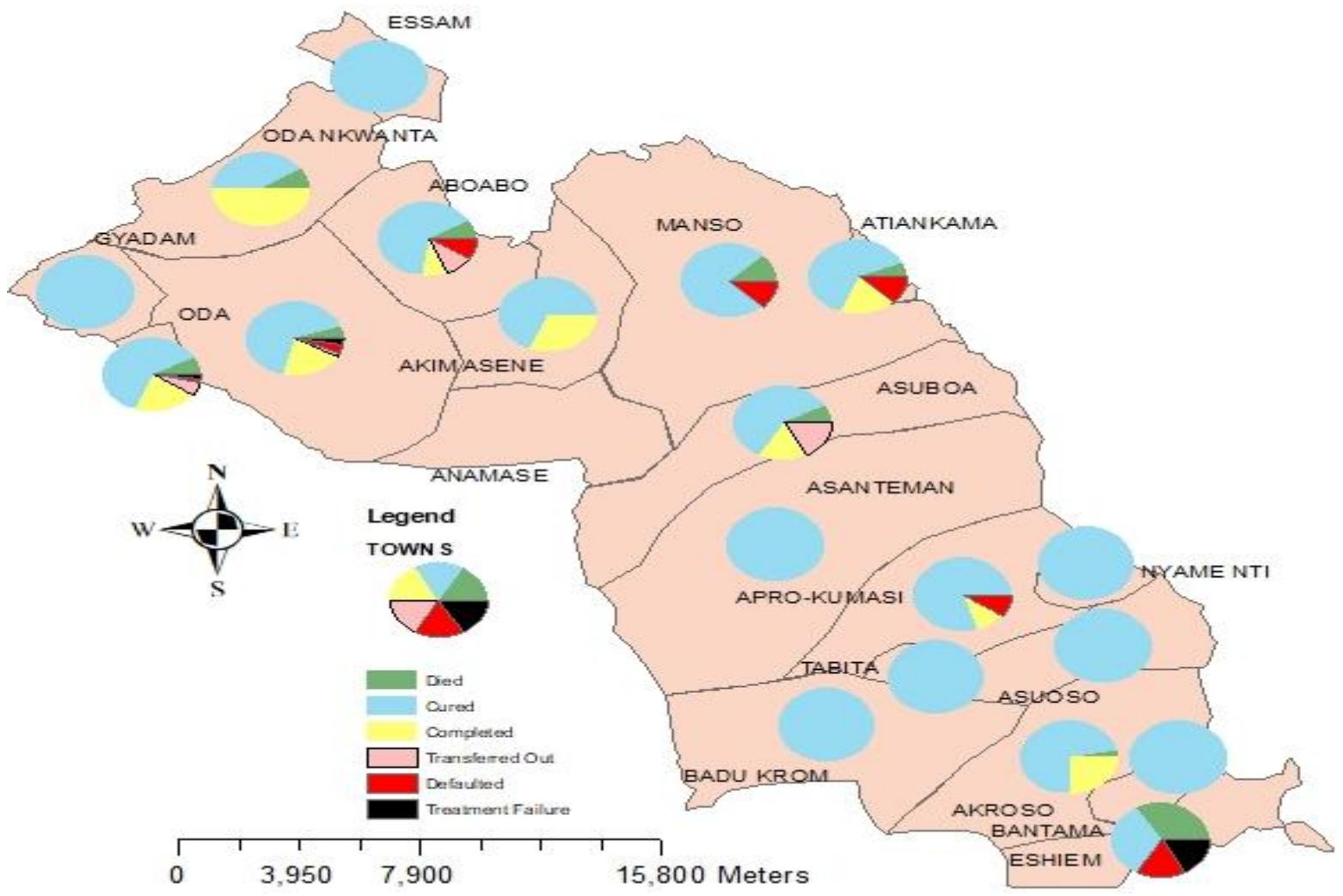

Figure 3: Treatment outcomes by communities, 2012-2016

\section{NUMBER OF DEFAULTERS 2012-2016}

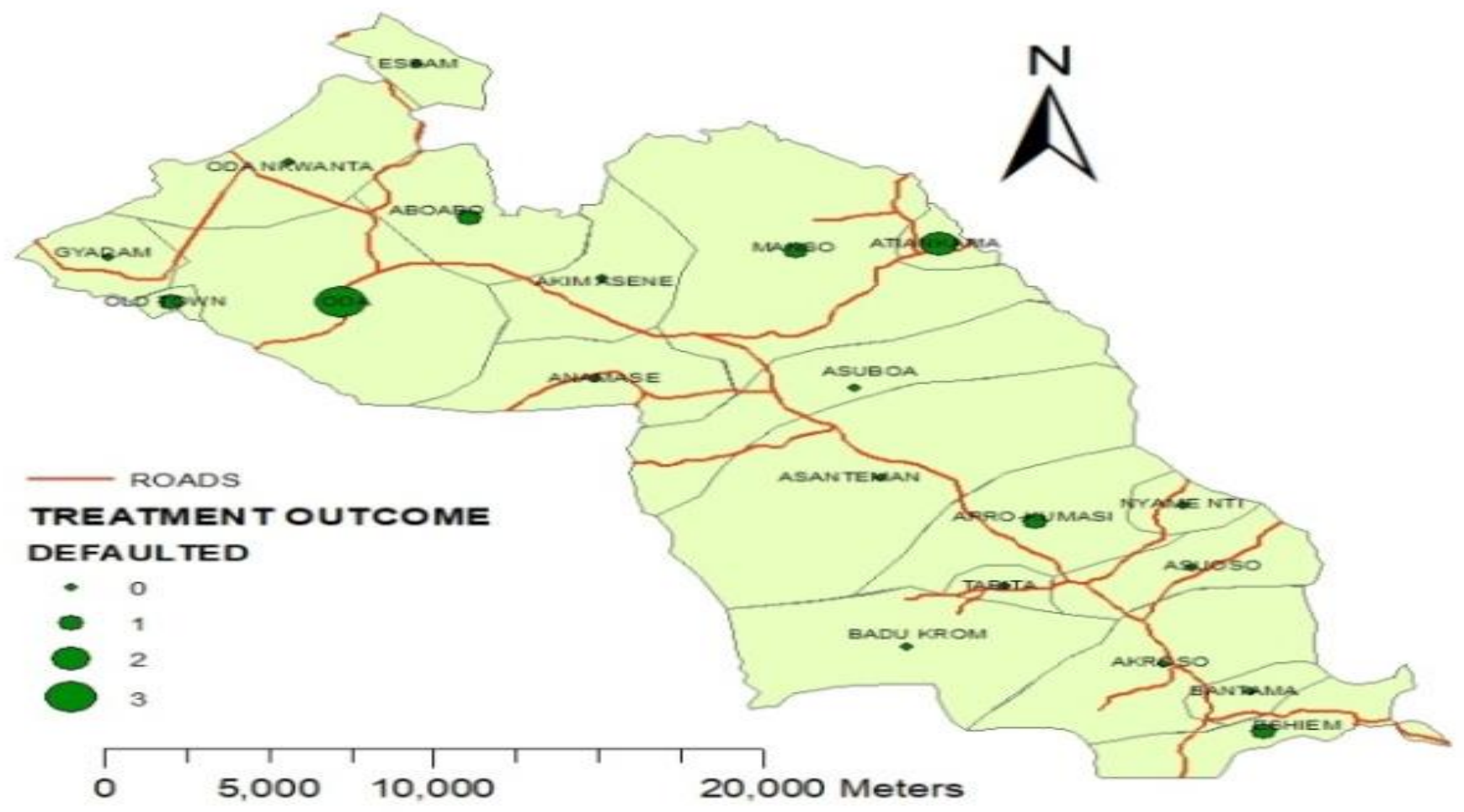

Figure 4: Defaulters distribution 2012-2016 


\section{NUMBER OF DEATHS $2012-2016$}

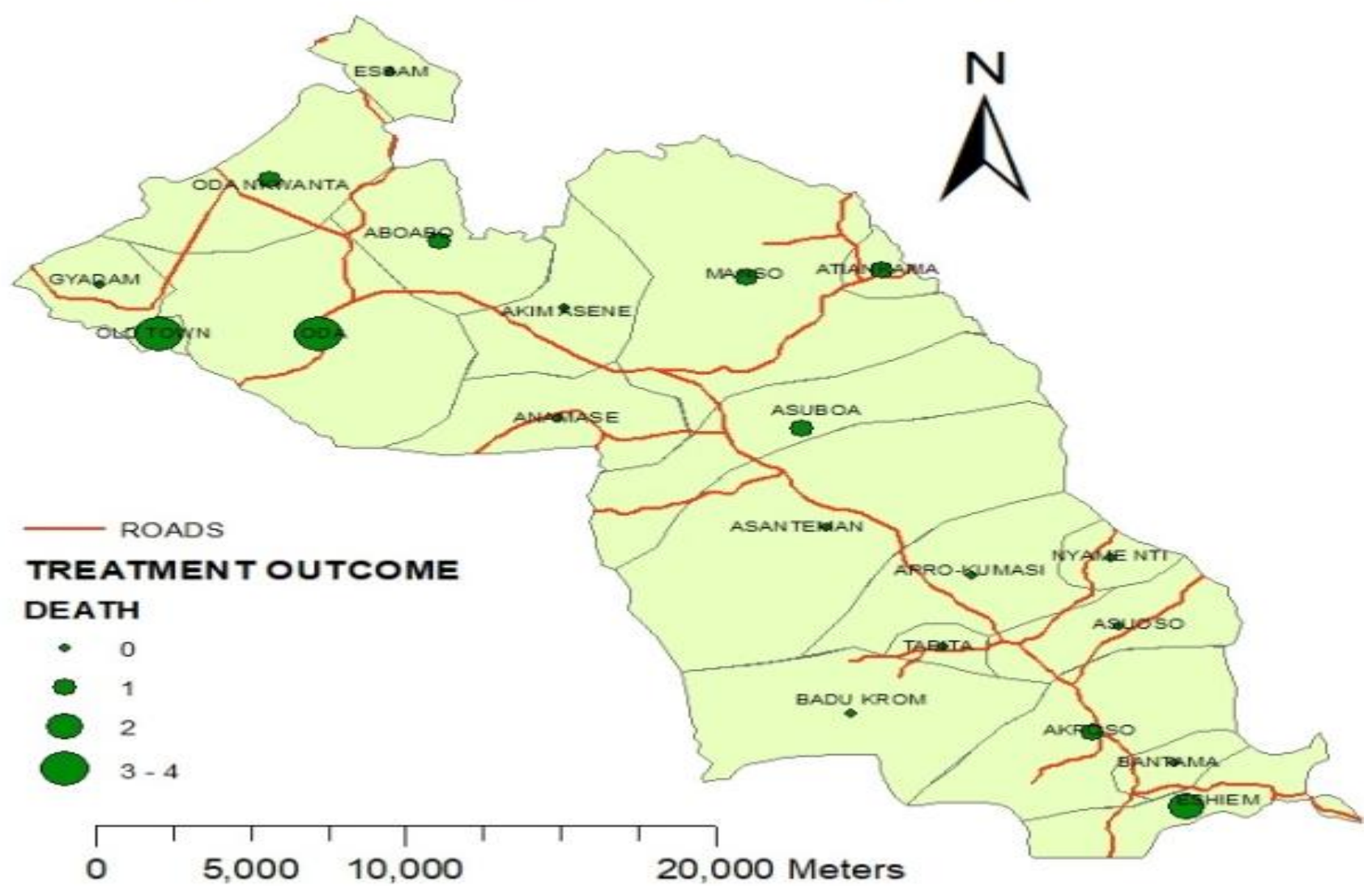

Figure 5: TB deaths distribution 2012-2016

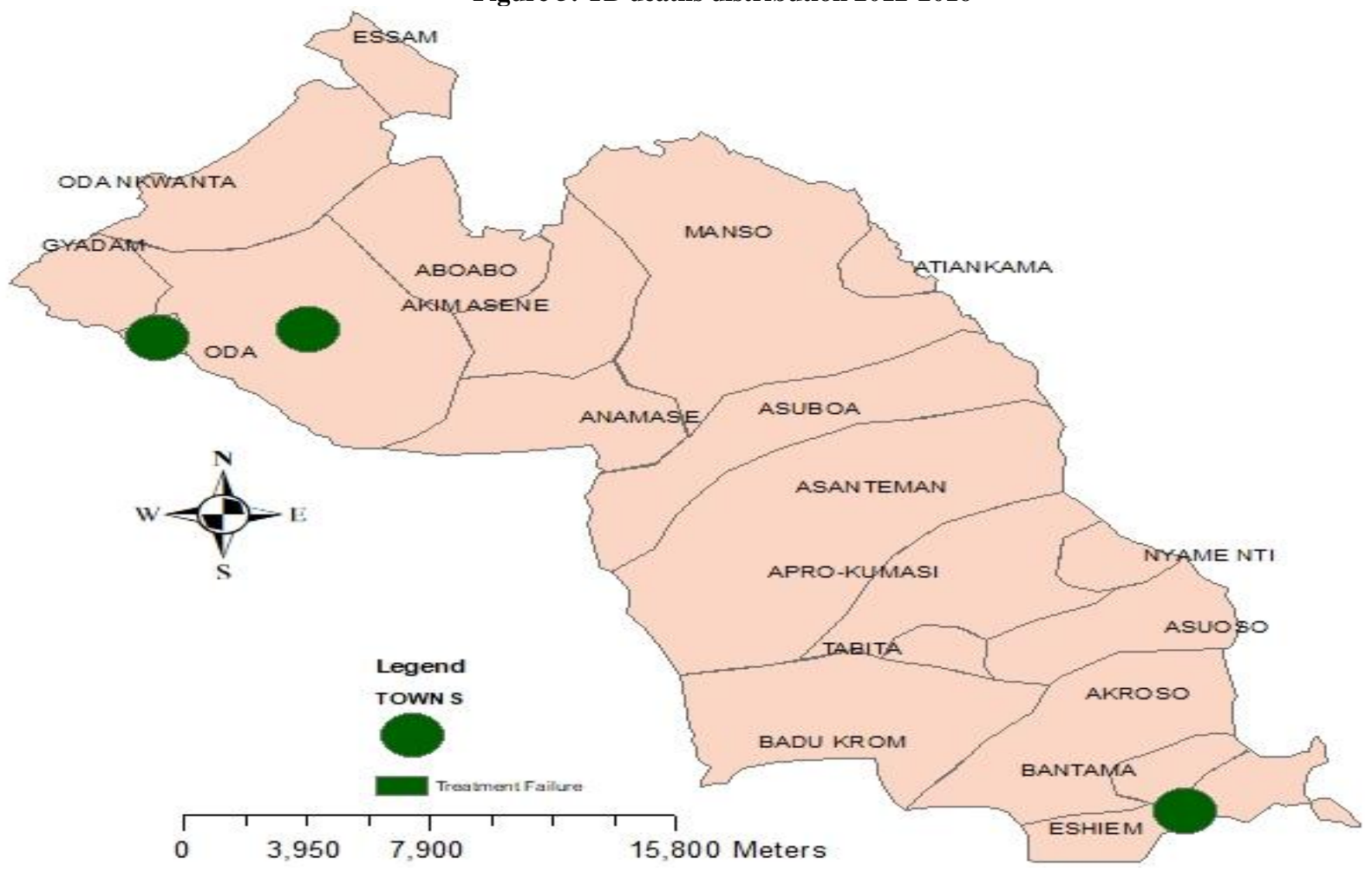

Figure 6: TB Treatment Failure 2012-2016, Birim Central 
The summary of the various treatment outcomes for the Birim Central municipality from 2012 to 2016 is presented in figure 7.

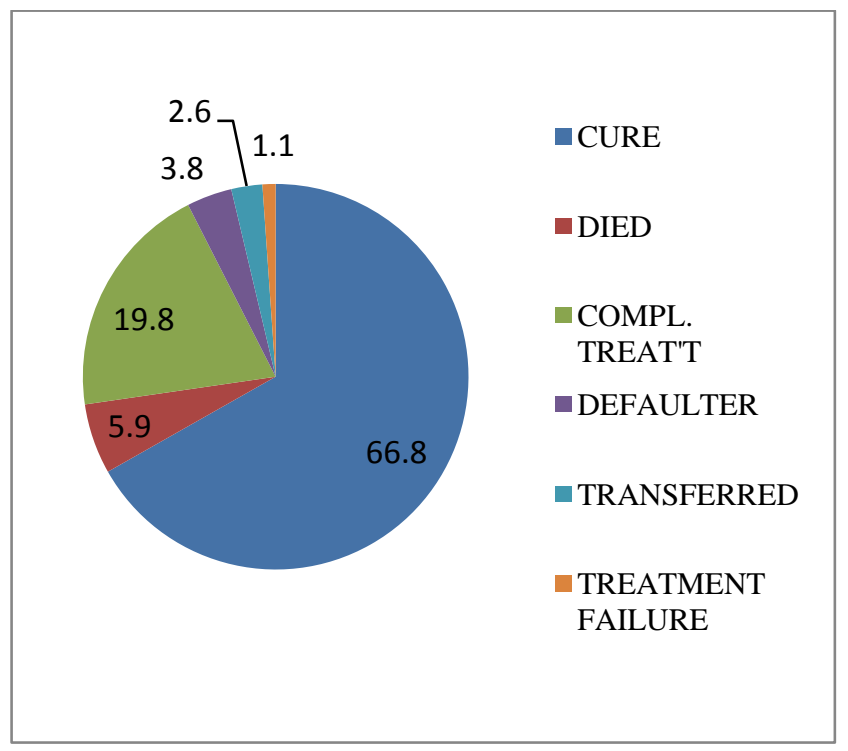

Figure 7: The five different treatment outcomes 2012-2016

\subsection{Proximity of health facilities to patients' location and influence on TB treatment outcome:}

How close or far a health facility is located to a patients' residence will likely impact the effectiveness of TB management within the municipality. To examine the issue of accessibility to healthcare, the study first looks at the health seeking behaviour and cost for TB patients. Patients were asked which facility they visited first when they began experiencing the cardinal sign of tuberculosis (coughing persistently). The results of this are presented in table 1 .

Table 1: Patients first point of call when coughing persistently

\begin{tabular}{ll}
\hline Patients First point of call & $\mathbf{N}(\%)$ \\
\hline Drugs store & $18(40)$ \\
Herbalist & $4(9)$ \\
CHPS compound & $19(42)$ \\
Hospital & $4(9)$ \\
& \\
Total & $45(100)$ \\
\hline
\end{tabular}

The responses from patients when asked the cost of reaching the nearest TB care facility for diagnoses; the responses are given in figure 8 .

\section{Cost of reaching the nearest TB care facility}

$$
\begin{aligned}
& \square \text { Up to GHc10 } \square \text { Up to GHc20 } \\
& \square \text { Up to GHc30 } \square \text { Up to GHc40 }
\end{aligned}
$$

$2 \% 2 \%$

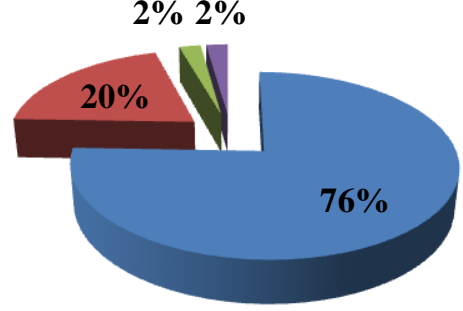

Figure 8: Transport cost to health facility

In order to evaluate the spatial accessibility to the health facilities from various parts of the study area, a network dataset had to be built using the road network of the Birim central municipality as presented in figure 9 .

\subsection{Measures to improve the control of tuberculosis in the municipality}

From the perspective of the patients, TB care can be improved in the municipality through the following means, as presented in table 2 . Twenty percent of the patients said there should be more education, $17 \%$ said health personnel should conduct TB screening in communities regularly, $10 \%$ said treatment site should be closer to community, and $17 \%$ said financial assistance should be provided for patients. $15 \%$ said stigmatization of patients should be reduced.

Table 2: Improving TB care (TB patients)

\begin{tabular}{ll}
\hline \multicolumn{1}{c}{ How to improve TB care } & N(\%) \\
\hline Do more education & $42(20)$ \\
$\begin{array}{l}\text { Health workers should conduct TB } \\
\text { screening in communities regularly }\end{array}$ & $35(17)$ \\
$\begin{array}{l}\text { Treatment site should be closer to } \\
\text { community }\end{array}$ & $21(10)$ \\
Provide more DOT points & $21(10)$ \\
Provide financial assistance & $37(17)$ \\
Reduce stigmatization & $32(15)$ \\
Visit patients very often in their homes & $24(11)$ \\
\hline
\end{tabular}


Table 3: Improving TB care (Health Staff)

\begin{tabular}{ll}
\hline \multicolumn{1}{c}{ How to improve TB care } & Response \\
\hline Conduct regular screening in the community & 16 \\
Conduct massive education & 15 \\
Prevent stigmatization & 10 \\
Give financial support to TB patients & 13 \\
Counsel TB patients regularly & 9 \\
Get TB prevention ambassador & 6
\end{tabular}

\begin{tabular}{ll}
\hline Motivate staff involve in TB care & 12 \\
Target specific populations for TB education & 5 \\
$\begin{array}{l}\text { Present annual statistics on TB to different } \\
\text { communities }\end{array}$ & 6
\end{tabular}
communities

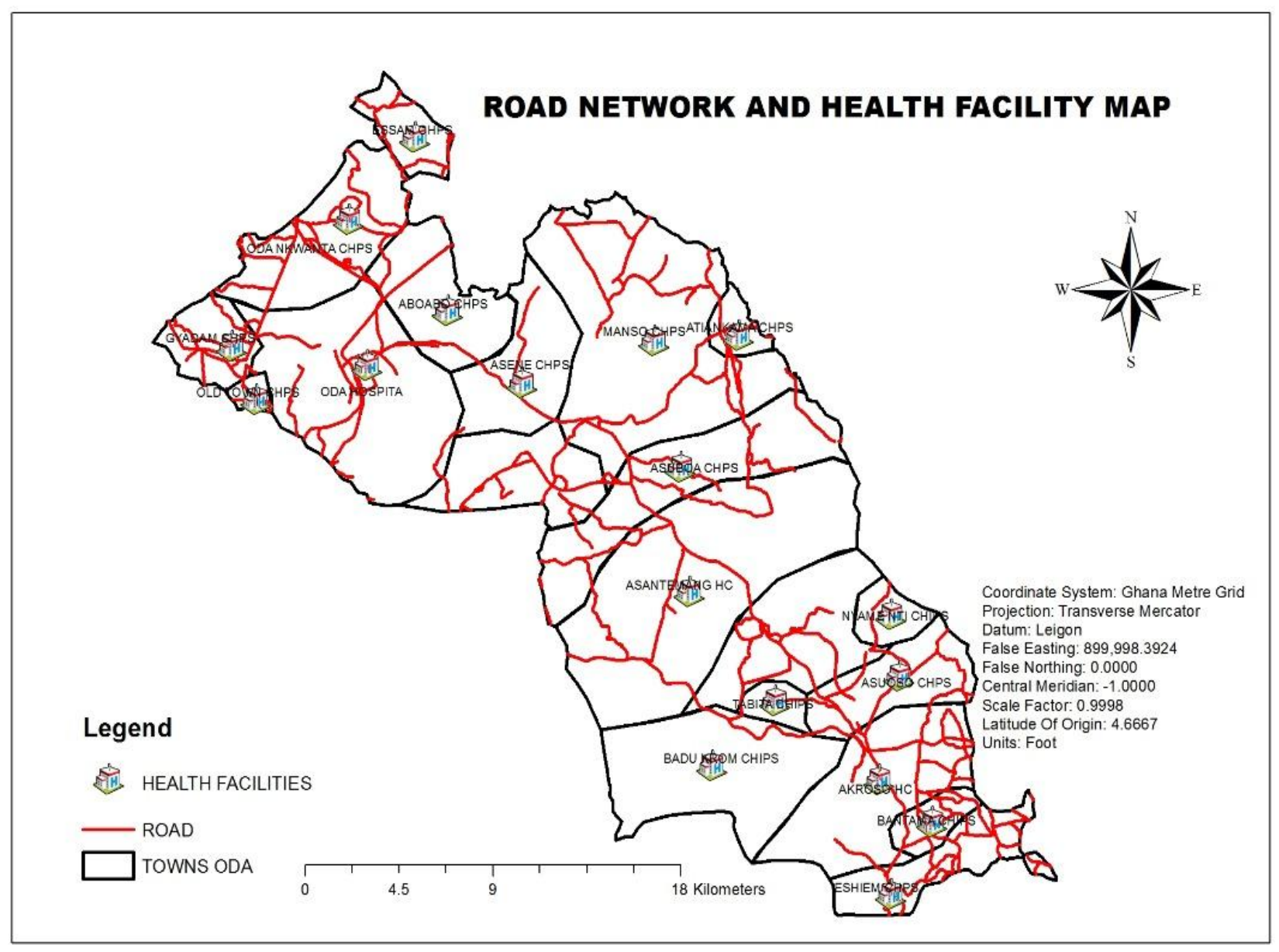

Figure 9: Road network Birim Central Municipality

\section{CONCLUSION}

The prevalence of TB for the five year retrospective period is high in Aprokumase, Oda Old Town, Akroso, Aboabo, Asene, and Eshiem. There is spatial relationship between these hot spots of TB and the kind of treatment outcome recorded (pvalue $=0.001$ ). A very large portion of the cases had positive treatment outcome which are treatment completed (19.8\%) and cured $(66.8 \%)$. These treatment successes match that of the national successes in TB treatment and thereby giving an indication that the municipality is on track in TB control. In this current study, a higher number of treatment successes are located in Akroso, Oda, Asene, and Atiankama. Adjusting for populations in the various communities, the treatment failure per 100,000 populations is very high in Eshiem community than in any other community. Similarly, Aprokumase,
Atiankama, and Eshiem recorded the higher defaulter rate per 100,000 populations.

How close or far a health facility is located from a patient is an important factor in determining whether patients will visit these facilities in order to get them managed or not. It is evident that patients will visit health facilities that are easily accessible and are close to them as most of the TB patients for the first time visited the CHPS compounds located in their localities when they exhibited the cardinal sign of TB. In terms of accessibility to TB care centers and diagnostic points, this has effect on the final treatment outcome as travelling longer distances to diagnostic centers for review of their sputum have effect on their finances. This could be the reason for some patients visit to herbalists, drugs stores, and CHPS compounds which are located close to them. An earlier study 
by $\mathrm{Li}$ et al (2016) also attributes poor treatment outcomes to clients staying far away from treatment centers. Again, travelling longer distances to sputum examination centers will have impact on the finances of the patient. An earlier study therefore recommended the inclusion of all peripheral facilities in the TB control program (Taser \& Wilkinson, 1999). As explained by Muture et al (2011), access to herbal preparation as in the case of this current study, contributes to treatment failure. However, Diefenbach-Elsobet et al (2017) relate poor treatment outcomes to social factors such as witchcraft and curses which are some of the things some TB patients in this study attributed their suffering to. This prevents patients from accepting fully the cause of their disease and thus has consequential effect on their treatment.

An important way of controlling TB disease suggested by both health staff and patients is to work strongly to reduce stigmatization. One way to do this is to direct education on the misconceptions about the disease (Deribew et al., 2010). Similarly, an earlier finding (Moller et al., 2011) supports this and concludes that reducing stigmatization will encourage suspected individuals to report as early as possible. Regular screening of the suspected individuals both at the health facility when they present with cough and also in the community on outreach basis will help detect more cases promptly and to treat them to halt further spread. A step to the control of the disease is for the municipality to get a prevention ambassador such as a formerly cured TB patient.

\section{REFERENCES}

[1] Yang, Y.R., McManus, D. P., Gray, D.J., Wang, X.L., Yang, S.K., Ross, A.G.,...Ellis M.K. (2012). Evaluation of the tuberculosis programme in Ningxia Hui autonomous region, the People's Republic of China: a retrospective case study. BMC Public Health.12:1110.

[2] Amo-Adjei, J. (2013a). Views of Health service providers on obstacles To tuberculosis control in Ghana.Infectious diseases of poverty journal.2:9.

[3] Li, X., Wang, L., Zhang, H., Jiang, S., Fang, Q., Chen, J., \& Zhou, X. (2014). Spatial variations of pulmonary tuberculosis prevalence co-impacted in People's Republic of China, 2010. BMC Public Health. 14:257

[4] Country Coordinating Mechanism [CCM], Ghana (n.d). Tuberculosis in Ghana. Retrieved from http://www.ccmghana.net/index.ph p/tuberculosis on 10th August, 2017

[5] Møller, V., Erstad, I., Cramm, J. M., Nieboer, A. P., Finkenflügel, H., Radloff, S., . . Kwizera, S. A. (2011). Delays in presenting for tuberculosis treatment associated with fear of learning one is HIV-positive. African Journal of AIDS Research, 10(1), 25-36.

[6] Kripalani, S., Jackson, A. T., Schnipper, J. L., \& Coleman, E. A. (2007). Promoting effective transitions of care at hospital discharge: a review of key issues for hospitalists. Journal of hospital medicine, 2(5), 314-323.

[7] Storla, D.G., Yimer, S., \&Bjune, G.A. (2008). A systematic review of delay in thediagnosisand treatment of tuberculosis. BMC Public Health. 8:15 DOI $10.1186 / 147-2458 / 8 / 15$

[8] Storla, D.G., Yimer, S., \&Bjune, G.A. (2008). A systematic review of delay in thediagnosisand treatment of tuberculosis. BMC Public Health. 8:15 DOI $10.1186 / 147-2458 / 8 / 15$
[9] Veen, J., Raviglione, M., Rieder, H.L., Miglior, G.B., Graf, P. Grzemska, M., \&Zalesky, R. (1998).Standard tuberculosis treatment outcome monitoring in Europe.Euopean Respiratory Journal.12: 505-510. Doi 10.1183/09031936.98.12020505

[10] World Health Organisation (1997). Treatment of tuberculosis. Guidelines for National Programmes.(2nd edition). Geneva.

[11] National Tuberculosis Control Program (NTP) (2012). Training Manual. Accra, Ghana: Acts Commercials.

[12] Tadesse, T., Demissie, M., Berhane, Y., Kebede, Y., \&Abebe, M. (2013). Long distance travelling and financial burdens discourage tuberculosis DOTs treatment initiation and compliance in Ethiopia: a qualitative study. BMC Public Health.13:424.

[13] Kolifarhood, G., Khorasani-Zavareh, D., Salarilak, S., Shoghli, A., \& Khosravi, N. (2015). Spatial and nonspatial determinants of successful tuberculosis treatment outcomes: An implication of Geographical Information Systems in health policy-making in a developing country. Journal of epidemiology and global health, 5(3), 221-230.

[14] Clarke, K.C., McLafferty, S. L., \&Tempalski, B.J. (1996). On epidemiology and geographic information systems: a review and discussion of future directions. Emerging infectious diseases.Vol. 2.No. 2. Page 85 - 92.

[15] Vine, M.F., Degnan, D., \&Hanchette, C. (1997). Geographic information systems: their use in environmental epidemiologic research. Environmental health perspectives. Vol. 105, No. 6, page 598-605.

[16] Gupta, R., \&Shriram, R. (2004). Disease surveillance and monitoring using GIS. Map India conference. Retrieved from https://www.researchgate.net/publication/237721111_DI SEASE_SURVEILLANCE_AND_MONITORING_USI NG_GIS on 12th November, 2017.

[17] Cromley, E. K., \& McLafferty, S. L. (2011). GIS and public health: Guilford Press.

[18] Wise, J. A., Thomas, J. J., Pennock, K., Lantrip, D., Pottier, M., Schur, A., \& Crow, V. (1995). Visualizing the non-visual: Spatial analysis and interaction with information from text documents. Paper presented at the Information Visualization, 1995. Proceedings

[19] Colantonio, A., Moldofsky, B., Escobar, M., Vernich, L., Chipman, M., \& McLellan, B. (2011). Using geographical information systems mapping to identify areas presenting high risk for traumatic brain injury. Emerging themes in epidemiology, 8(1), 7.

[20] Mills, H. L., Cohen, T., \& Colijn, C. (2011). Modelling the performance of isoniazidpreventive therapy for reducing tuberculosis in HIV endemic settings: the effects of network structure. Journal of the royal society interface, rsif20110160.

[21] Huang, B., Dignan, M., Han, D., \& Johnson, O. (2009). Does distance matter? Distance to mammography facilities and stage at diagnosis of breast cancer in Kentucky. The Journal of Rural Health, 25(4), 366-371

[22] Li, D., Ge, E., Shen, X., \& Wei, X. (2016). Risk factors of treatment outcomes for multi-drug resistant 
tuberculosis in Shanghai, 2009-2012. Procedia environmental sciences.36 (2016), 12-19. Doi 10.1016/j.proenv.2016.09.003

[23] Tanser, F., \& Wilkinson, D. (1999). Spatial implications of the tuberculosis DOTs strategy in rural South Africa: a novel application of geographical information system and global positioning system technologies. Tropical medicine and international health.Volume 4, no.10, pp634-638.

[24] Muture, B.N., Keraka, M.N., Kimuu, P.K., Kabiru, E.W., Ombeka, V.O., \&Oguya, F. (2011). Factors associated with default from treatment among tuberculosis patients in nairobi providence, Kenya: a case control study. BMC public health.11:969.

[25] Diefenbach-Elstob, T., Plummer, D., Dowi, R., Wamagi, S., Gula, B., Siwaeya, K., ...Warner, J. (2017). The social determinants of tuberculosis treatment adherence in a remote region of Papua New Guinea.BMC Public Health.17: 70. Doi 10.1186/s12889-016-3935-7

[26] Deribew, A., Abebe, G., Apers, L., Jira, C., Tesfaye, M., Shifa, J., Bezabih, M. (2010). Prejudice and misconceptions about tuberculosis and HIV in rural and urban communities in Ethiopia: a challenge for the TB/HIV control program. BMC public health, 10(1), 400. 